\title{
EL SER HUMANO FRENTE A LA CRISIS DEL VÍNCULO SOCIAL
}

\author{
Julián González Torres \\ Departamento de Filosofía \\ Universidad Centroamericana José Simeón Cañas \\ jgonzalezt@uca.edu.sv \\ Aceptado 05/11/16 \\ Recibido 28/11/16
}

En primera instancia, pensar el vínculo social podría remitirnos al análisis de un conjunto de valores en virtud de los cuales la persona realiza su vida en un amplio y complejo proceso de humanización. En sociedades corroídas por la violencia y la corrupción política (de izquierdas y de derechas), como es el caso de El Salvador, se ha hecho lugar común afirmar que las personas han perdido los valores; de manera que superar la crisis del vínculo social pasaría principalmente por la recuperación de los valores perdidos. Este tipo de postura remite a una segunda: la familia es el núcleo donde surge la raigambre del vínculo social, por lo que para comprender la crisis del vínculo habría que analizar cómo las familias educan a sus hijos. Ambas posturas se resumirían en un llamado colectivo: ¡Hay que recuperar los valores desde la familia! Una tercera postura podría sugerir que el vínculo social está configurado y materializado en el funcionamiento de las instituciones sociales: estas serían las garantes de un adecuado vínculo entre las personas, por lo que habría que analizar críticamente cómo están funcionando las instituciones destinadas al cuido del vínculo social.

El problema con la primera postura es que aun cuando los valores son relevantes en el proceso constitutivo y constituyente del vínculo social, este no se limita a ser una fuente de valores para la persona. En la configuración social de su persona, el individuo aprende valores, pero el vínculo social es algo más rico, más complejo y, sobre todo, más radical que un conjunto de valores (de corte religioso, por ejemplo). Respecto a la segunda postura hay que señalar que la familia es una de las instituciones importantes donde se inicia el forjamiento del vínculo social, pero no podemos partir de ella en un análisis que pretende ser radical, puesto que el vínculo social tampoco se limita al lazo familiar. En cuanto a la tercera postura, habrá que advertir que en la institución no descansa lo más radical (lo más "vivo" podríamos decir). Es más, las instituciones pueden estar socavando el vínculo social (y de hecho es así). Comenzar con las instituciones no es un buen principio para comprender la radicalidad del vínculo social.

Para una filosofía social fresca y renovada, la mejor herramienta para comenzar el análisis del vínculo social es la praxeología de Antonio González. ${ }^{1}$ Si queremos

1 Consultar la tesis de doctorado de Antonio González: Un solo mundo. La relevancia de Zubiri para la teoría social; consultar también los siguientes libros: Estructuras de la praxis. Ensayo de una filosofía primera y Surgimiento. Hacia una ontología de la praxis. 
comprender la radicalidad y la importancia del vínculo social debemos partir del análisis de la praxis humana. Una virtud de la praxeología de González es que de entrada se aparta del peso asfixiante de la subjetividad moderna. Los actos humanos son el punto de partida de su propuesta de filosofía primera. Pero no los actos de algún supuesto sujeto, de un yo o de una conciencia continente de contenidos. Según el filósofo español, los actos son el surgir de las cosas. En el acto de ver, veo cosas; en el acto de tocar, siento cosas; en el acto de escuchar se presentan cosas; y cuando pienso o imagino, también surgen cosas, incluso en el acto de soñar surgen cosas. Ahora bien, entre el acto y lo que surge hay un desgarramiento por alteridad radical: el acto no es la cosa que surge, en al acto surge la cosa y esta cosa que surge no queda remitida al acto; al surgir la cosa no remite más que a sí misma como cosa. Entre el acto y la cosa que surge hay una alteridad radical, es decir, una radical independencia. Pero los actos son el surgir de las cosas. Entenderemos por cosa un sistema de propiedades que surge en el acto. De acuerdo a esta definición, cosa es el bus que veo venir, el canto del pájaro que escucho, el libro sobre el escritorio y la persona a quien saludo por la mañana. Esto no significa que la filosofía de Antonio González reduce la persona a cosa, lo que sucede es que estamos frente al análisis elemental (primario) de una filosofía primera que define a la cosa como un sistema de notas o de propiedades que están en interdependencia funcional entre sí.

En su libro Estructuras de la praxis, González distingue entre actos sensitivos, afectivos y volitivos. La unidad sistemática entre sensaciones, afecciones y voliciones constituye la acción humana. No se trata de una unidad en orden de sucesión entre actos de sensación, actos de afección y actos de volición, sino de una unidad sistemática. Se da una interdependencia funcional entre los tres tipos de actos, y en eso consiste la acción como sistema. Pero cada acto de la acción como sistema se da en alteridad respectiva con los otros. Lo sensitivo no queda reducido a lo afectivo, ni esto a lo volitivo, sino que los tres tipos de actos se dan en alteridad estructural en la acción. Para que la acción cobre sentido (significado) incorpora un nuevo tipo de acto: el acto intelectivo. Se trata de la acción con sentido, llamada actuación por el autor. Por la acción, el ser humano es un agente; por la actuación, es un actor. Para comprender la radicalidad y la relevancia del vínculo social podemos quedarnos solo con las acciones, teniendo siempre presente que en realidad vivimos socialmente en medio de actuaciones.

La acción humana es esencialmente abierta, pero no porque se den actos intelectivos que introduzcan una distensión entre la afectación de las cosas y la respuesta que el individuo da a las cosas. La acción humana es abierta por algo más radical. Entre los actos y las cosas hay una alteridad radical: ni el acto es la cosa ni la cosa es el acto, entre el acto y la cosa hay una independencia radical. La cosa no queda remitida al acto, solo remite a sí misma, lo que no impide (obviamente) estudiar en profundidad qué son las cosas. De hecho este es el reto y el trabajo del logos científico. Pero instalados en una filosofía primera es importante remarcar que entre acto y cosa hay una alteridad radical, y es por esta alteridad que se da la radical distensión entre la acción y las cosas. Esa distensión entre los actos y las cosas es lo que hace de la acción una acción abierta, es decir, una acción humana. Mientras los animales no humanos responden con respuestas fundamentalmente cerradas, las respuestas del ser humano son 
fundamentalmente abiertas y en esto radica el carácter humano de la acción. Lo humano de la acción no estriba en una mediación simbólica, lingüística o consciente. La acción es humana por esa radical distensión entre los actos y las cosas. En esta distensión radica el carácter personal de la acción. En esa distensión descansa la intimidad de la acción. La intimidad no es lo más apartado o lo más oculto a los demás, la intimidad tiene su raíz en la radical distensión de los actos. La respuesta que doy es mía desde esa esencial y constitutiva distensión que se da por la alteridad radical. Entonces: ¿cómo surge lo social en la acción?

Otra forma de decir que en los actos surgen cosas es decir que en los actos se actualizan cosas. La idea del "surgir" es más reciente, aparece en el libro Surgimiento (2014). En Estructuras de las praxis predomina la idea de la actualización de las cosas. A fin de comprender, coincidamos en que estamos hablando del hecho de que en los actos aparecen/surgen las cosas. Así pues, los otros también se actualizan en los actos. Sin embargo, lo medular de lo social no radica en la actualización de los otros. Lo decisivo está en que los demás se insertan e intervienen en el transcurso de mi vida, más allá de ser consciente o no de esa intervención. Así lo plantea el autor: "El carácter social de las acciones no está primariamente en que los otros se actualicen en los actos que las integran, sino ante todo en que los demás intervienen sobre el transcurso mismo de la acción. En esto consiste precisamente el «poder» social: en que los demás pueden determinar el transcurso de mis acciones" (González, 1997, 96).

Según González, las teorías de la sociedad de mayor circulación han priorizado la dimensión simbólica al momento de estudiar el vínculo social, cuando en realidad la acción es social porque los otros intervienen en el transcurso de la acción, independientemente de que seamos conscientes o no de dicha intervención, o de que compartamos o captemos los mismos símbolos. El autor agrega: "cuando soy consciente de la presencia de los demás, ellos ya se habían insertado en mi intimidad personal, interviniendo sobre el transcurso de la acción" (González, 1997, 97). La mediación simbólica es relevante, y sin ella sería inviable la vida humana en sociedad; pero estructuralmente antes de toda cosmovisión simbólica y de cualquier conciencia personal de la presencia de los otros en mi vida, los demás ya han intervenido en la configuración de mi persona. La modulación del ser personal por la intervención de los demás conserva una estructura radical más poderosa que cualquier tipo de mediación simbólica (de sentido). Hemos dado, entonces, con el carácter radical del vínculo social: es la intervención de los demás en el transcurso de mis acciones. Ahora bien, ¿cómo explicar la crisis de las sociedades contemporáneas a partir (de la crisis) del vínculo social? Estamos frente a la profunda importancia del vínculo social

Los otros intervienen en mis acciones permitiéndome o impidiéndome el acceso a las cosas. En este punto se juega lo más crucial del vínculo social, ya que el acceso a las cosas es fundamental en el proceso de realización de la persona. Toda persona, por la radical distensión entre los actos y las cosas, está abocada (llamada) a realizarse. El acceso a cosas no es más que el constitutivo proceso en virtud del cual cada individuo accede a aquellos elementos sin los cuales no podría realizarse de forma digna. En tal sentido, la realización de la persona no refiere principal y radicalmente a una esfera de principios y 
de valores (religiosos, por ejemplo), como algunos insisten con cansina obstinación. La realización de la persona remite inexorablemente a cosas sin las cuales no habría humanización en el sentido genuino del término. Esto no descarta los principios y valores religiosos, pero tampoco los sitúa en la estructura medular. Entonces: ¿a qué cosas accedemos?

Ciertamente, accedemos a cosas variadas, complejas y distintas producidas por la praxis humana. Sin embargo, en virtud de la realización humana, cada persona necesita acceso a cosas sin las cuales no podría vivir con dignidad. Por tanto, las cosas que la persona necesita son alimento, hogar, amor y protección, salud, vestido, educación, formación cultural, recreación, autonomía, ciencia y saber en general. Desde el enfoque de Martha C. Nussbaum (2007 y 2012), podemos afirmar que la persona requiere capacidades para vivir con dignidad. El escándalo contemporáneo radica en la obscena desigualdad en cuanto al acceso a estas cosas se refiere. Por el vínculo social tenemos o no tenemos acceso a estas cosas, necesidades o capacidades, según la perspectiva que prefiramos.

Ahora bien, el vínculo social no está hecho de otra cosa que de acciones humanas, justamente las que hacen posible el acceso o el no acceso a los bienes para vivir con dignidad. Por tanto, para encaminarnos hacia un orden social justo es indispensable "volver" a ese vínculo social y desde allí comenzar a desestructurar las injusticias legitimadas desde las instituciones sociales (las del Estado, las del capitalismo, las de la religión, entre otras). Por eso es que en nuestro análisis no tomamos como punto de partida las instituciones. Lo más radical para comprender el vínculo social es la praxis humana, el conjunto de actos que constituyen la actividad humana. Mu- chas instituciones políticas y económicas, por ejemplo, están socavando la praxis viva de las relaciones humanas. Tampoco es útil la perspectiva de los valores como punto de partida del análisis. Los valores y los símbolos son relevantes, pero no nos ofrecen la dimensión más radical, que sí encontramos en los actos como el surgir de las cosas.

Pensar el vínculo social quiere decir "volver" al núcleo de nuestras acciones y desde allí reconstruir el vínculo social con miras a luchar por una sociedad verdaderamente justa, es decir, una sociedad que renuncie a la maldición de Trasímaco, pues este afirmaba que "lo justo no es otra cosa que lo que conviene al más fuerte". ${ }^{2}$ El capitalismo, como sistema económico, no es más que la imposición del más fuerte, y en la medida en que esto no se revierta, las instituciones capitalistas tendrán en crisis perenne la raíz del vínculo social, es decir, el acceso de las personas a las cosas indispensables para una realización humana con dignidad.

\section{FUENTES CONSULTADAS}

González, A. (1994). Un solo mundo. La relevancia de Zubiri para la teoría social, Universidad Pontificia de Comillas, Madrid.

González, A. (1997). Estructuras de la praxis. Ensayo de una filosofía primera, Trotta y Fundación Xavier Zubiri, Madrid.

González, A. (2014). Surgimiento. Hacia una ontología de la praxis, Universidad de Santo Tomás, Bogotá.

Nussbaum, M. C. (2007). Las fronteras de la justicia. Consideraciones sobre la exclusión, Paidós, Barcelona, 2007, especialmente las páginas 82-92.

Nussbaum, M. C. (2012). Crear capacidades. Propuesta para el desarrollo humano, Paidós, Barcelona, 2012.

2 Platón, República, 338 c. 